\title{
Survey of General Aviation Pilot Reports (PIREPs) Conformity, Consistency, and Quality
}

\author{
MICHAEL E. SPLITT \\ Florida Institute of Technology, College of Aeronautics, Melbourne, Florida \\ MORGAN HENNARD \\ École Nationale de l'Aviation Civile (ENAC), Toulouse, France \\ PIERRE BOUGEARD \\ École Nationale de l'Aviation Civile (ENAC), Toulouse, France
}

(Manuscript received 26 February 2021; review completed 10 August 2021)

\begin{abstract}
Understanding barriers to submitting pilot weather reports (PIREPs) has been the focus of recent attention in the general aviation community. The goal is to help increase the submission frequency of these reports, which are valuable for aviation operations and situational awareness. Additionally, the perception of the quality of these reports by pilots can impact the level of trust users have in the data. This study aims to evaluate aspects of the reporting frequency and quality of PIREPs particularly from the general aviation perspective. PIREPs were subjected to a range of logical, qualitative, and quantitative tests. Commercial applications are shown to improve the data quantity transmitted in the reports, particularly the non-mandatory sections such as sky and weather conditions, as well as to help alleviate some of the transcription errors. Reported times of the PIREPs indicate impacts from rounding that may limit the utility of the data in some instances. Analysis of individual geophysical measurements show varying quality with potential gaps noted in the icing type assessment and a bias towards higher turbulence intensity reporting, though air temperature compares well to independent data.
\end{abstract}

\section{Introduction}

Pilot weather reports (PIREPs), often termed just pilot reports, play a crucial role in the National Airspace System (NAS) ranging from providing situational awareness for pilots to supplying data for air traffic control operations (Johnson et al. 2019). The vital importance of PIREPs received special focus in a recent investigation report issued in 2017 by the National Transportation Safety Board (NTSB 2017) focused on improving the submission rate of PIREPs and the dissemination of those PIREPs within the NAS. This report examined barriers to PIREP submission, accuracy of reports, and recommendations on improving the solicitation and dissemination of PIREPs.

Verbal transmission of the PIREP via radio to Air Traffic Control (ATC), directly or via dispatchers or other personnel, is the dominant form of submission.
This additional handling of the PIREP information was noted to be a source for error introduction and, at times, a barrier to transmission. Both the NTSB report and work by Casner (2010) suggest that pilots' lack of confidence in understanding the PIREP format and their ability to ascertain the weather conditions are barriers to the submission of PIREPs. The work by Casner (2010) also revealed that pilots, though viewing them favorably, felt that many PIREPs can have issues with accuracy. Blickensderfer et al. (2017) examined general aviation (GA) pilots' understanding in a wide area of aviation meteorology products. The pilots surveyed in this study correctly answered four questions regarding PIREPs $77.7 \%$ of the time, though the pilots surveyed were not limited to GA. PIREP usefulness in a meteorological context has mixed reviews. Gultepe et al. (2019) noted shortcomings in PIREP turbulence and icing reports in multiple studies and recommended improvements

Corresponding author address: M. E. Splitt, College of Aeronautics, Florida Institute of Technology, 150. W. University Blvd, Melbourne, FL 32901.

E-mail: msplitt@fit.edu 
to the PIREP system. From a different perspective, James et al. (2020) studied the impact of the reduction in commercial aircraft weather observations because of the COVID-19 pandemic and found significant impacts on the forecast skill in a numerical weather prediction model. Here we will focus on the quality of PIREPs from the GA community.

The Partnership to Enhance General Aviation Safety, Accessibility and Sustainability (PEGASAS) is a Federal Aviation Administration (FAA) Center of Excellence for General Aviation. The mission of PEGASAS includes enhancing weather technology in the cockpit (e.g., Johnson et al. 2017). As part of the PEGASAS Augmented Weather Interfaces Project, evaluations of PIREPs submitted via commercial-offthe-shelf (COTS) systems and those via traditional submission pathways were conducted. The research broadly focuses on questions of GA PIREP gaps or successes in submission pathways or quality. The focus of this PEGASAS research is to assess factors that impact PIREPs' report content and quality especially as pertaining to GA pilots, including analysis based on reporting tool methods. Quality of the reports is addressed qualitatively and quantitatively including logical limit checking and the comparison of the reports to meteorological analyses. This includes comparative statistics related to frequency of reports, types of reports, types of aircraft reporting, assessment of altitude error, and consistency checks.

\section{Data and methods}

Data sets used in this study include archived PIREPs obtained from the NAS. Ancillary data sets, such as those used in graphical information systems, were used to provide additional context and were obtained from multiple sources, including the Aviation Weather Center (AWC). Meteorological data were collected from the National Oceanographic and Atmospheric Administration (NOAA) for comparative evaluations of atmospheric icing and turbulence.

\section{a. PIREPS}

Five years of PIREP data (from 2015 through 2019, courtesy of Iowa State University, mesonet. agron.iastate.edu/archive/) were included in this study, a total of over 2.5 million reports. Aircraft reports (a more routine and automated weather report from aircraft) were not evaluated as part of this study. With indicators in the remarks section of the PIREPs, it was possible to identify some specific submission tools or pathways (e.g., AEROVIE, AWC-WEB) used to submit the reports. Reports were classified into entry method classes based on comments in the remark (/RM) section of the PIREP. If the remark contained the text AEROVIE ${ }^{1}$ for the related electronic flight bag, it was classified as such. If the remark contained AWCWEB, it was classified as that. Any other report was then classified as nominal. The entry interface for the PIREP submission tool for the AEROVIE application (NTSB 2017) and the AWC web application (Vietor 2018) provide different approaches for PIREP user data entry. The AEROVIE interface uses many icons to help guide the pilot through the PIREP entry process, whereas the AWC-WEB interface provides a more sequential approach through the required and optional PIREP entries.

Reports were identified as GA by use of an International Civil Aviation Organization (ICAO) listing of aircraft types that included weight class and engine type. The criteria used to identify likely GA aircraft were whether the aircraft either 1) was in the light-weight class category, 2) had a piston engine, or 3) was included in a most-used GA jets listing (provided in the Appendix) from the General Aviation Manufacturers Association (GAMA 2016). Guidance on proper formatting for PIREPs is provided in the Federal Meteorological Handbook No. 12: United States Meteorological Codes and Practices (OFCM 1998), FAA Job Order (JO) $7110.65 Y$ on Air Traffic Control (FAA 2019), and FAA JO 710.10BB on Flight Services (FAA 2021b). Typographical errors within the reports were a noted issue in the data analysis but are not a focus here, though they may indicate that additional word-checking procedures could be of value in some PIREP reporting tools or software.

\section{b. Geographic data}

Freely available GIS shapefiles that defined political boundaries of countries, states, and territories as well as FAA Air Route Traffic Control Centers (ARTCC) regions were used to isolate regional frequencies of PIREP submissions. GA statistics on annual flight hours by state (FAA 2021a) for the most recently available years of 2012-2015 were used to help normalize report frequency because flight activity varies significantly by state. Terrain elevation data were used to provide a

\footnotetext{
${ }^{1}$ The Aerovie application is now available as Stratus Insight
} 
basic quality check of the reported flight level in terms of whether the reported altitude was above ground level for the reported location. Global Multi-resolution Terrain Elevation Data (GMTED) with 30 arc-sec (approximately 1-km) resolution (Danielson and Gesch 2011) were downloaded from the Multi-Resolution Land Characteristics Consortium (Wickham et al. 2014). Additionally, these data were processed into a file that provided the minimum elevation within a $10-\mathrm{km}$ circular region of each grid point using Geospatial Data Abstraction Library software libraries (GDAL/OGR 2018) to account for some uncertainty in the reported PIREP location. Gray-shaded images of the raw and filtered datasets are shown in Fig. 1 and exemplify the impact of the smoothing procedure in the intermountain western United States.

Some analyses of the regional frequency of specific weather phenomena were conducted. For example, PIREPs that included an indication of mountain wave activity were pulled from the data set and plotted (not shown here). Most of the mountain wave reports were reasonably within zones of mountainous terrain, but there were many instances of mountain wave reports in regions such as Illinois and Florida. Whether these were erroneous reports or encounters with atmospheric motions like those encountered with mountain waves is unknown, but it is worth noting a potential gap in observing or reporting such phenomena within PIREPs.

\section{c. Gridded meteorological data}

Gridded output from the AWC Graphical Turbulence Guidance (GTG; Sharman et al. 2006) Clear Air Turbulence (CAT) product in gridded binary (GRIB) format have been collected from the National Centers for Environmental Prediction (NCEP) and archived at the Florida Institute of Technology since late in 2018. CAT eddy dissipation rate (EDR) data from the year of 2019 were used for this study for a comparative analysis of the turbulence intensity reported in PIREPs and were adjusted for aircraft type. Though PIREP turbulence reports are expected to provide a more qualitative assessment of the turbulence intensity (Schwartz 1996), and the use of EDR sensors (e.g., Sharman et al. 2014) can provide more quantitative turbulence intensity observations, our goal here is to understand the general quality of PIREP turbulence reports from the GA community. For the year 2019, turbulence intensity from GA reports were compared to nearest estimates from the GTG product 1-h forecast of CAT. Reports
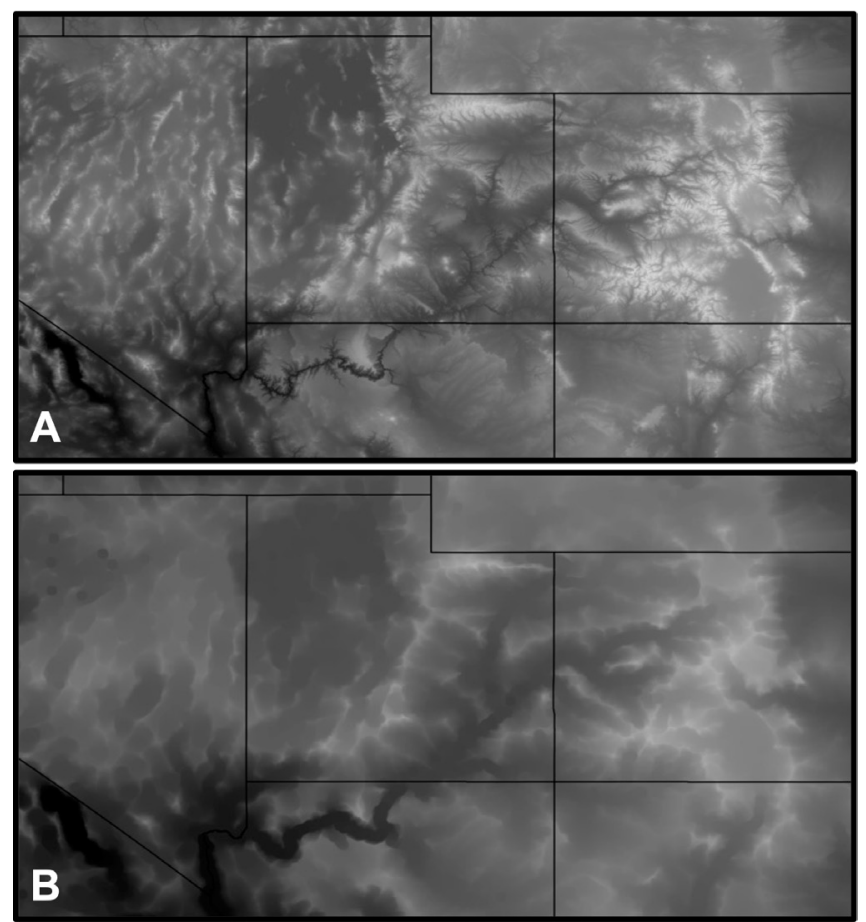

Figure 1. Gray-shaded raw (A) and filtered (B) GMTED elevation data for a portion of the dataset over the Intermountain Western U.S. Click image for an external version; this applies to all figures hereafter.

that were noted to be within or near convective clouds (e.g., towering cumulus, cumulonimbus) or lightning were removed from the data set. GTG EDR values were converted to a turbulence intensity category based on AWC thresholds (Table 1) accounting for aircraft type using the ICAO listing noted earlier. The light aircraft category accounted for $73.5 \%$ of the reports used and $26.5 \%$ were in the medium aircraft category. No GA aircraft used were identified as heavy. Similarly, icing severity estimates from the AWC Current Icing Potential (CIP) severity product (Bernstein et al. 2005) in GRIB format were collected and archived from NCEP and used for a comparative analysis of icing intensity for the year of 2019. Icing intensity reports from PIREPs were compared to the nearest proximity CIP icing intensities (i.e., icing severity).

The NCEP/National Center for Atmospheric Research (NCAR) Reanalysis (Kalnay et al. 1996) is a 3D state-of-the-art analysis/forecast system that performs data assimilation using past data from 1948 to the present. Reanalysis temperature data were acquired from the website for the NOAA Earth System Research Laboratory's Physical Sciences Laboratory in Boulder, Colorado (psl.noaa.gov/). The reanalysis temperature 
Table 1. Thresholds for conversion of GTG EDR to turbulence intensity category.

\begin{tabular}{|l|c|c|c|c|}
\hline \multirow{2}{*}{\multicolumn{1}{|c|}{ ICAO Weight Class }} & \multicolumn{4}{|c|}{ Eddy Dissipation Rate Threshold $\left(\mathbf{m}^{\mathbf{2}} / \mathbf{s}^{\mathbf{2}}\right)$} \\
\cline { 2 - 5 } & Light & Moderate & Severe & Extreme \\
\hline Light & 0.13 & 0.16 & 0.36 & 0.64 \\
\hline Medium & 0.15 & 0.20 & 0.44 & 0.79 \\
\hline Heavy & 0.17 & 0.24 & 0.54 & 0.96 \\
\hline
\end{tabular}

data provide a way to quantitatively assess temperatures reported in PIREPs.

\section{Analysis and discussion}

\section{a. PIREP classification and reporting trends}

\section{1) ENTRY METHOD AND GA CLASSIFICATION}

Classification criteria for identifying GA PIREPs were noted earlier in the data section. GA accounts for $37.4 \%$ of the reports in the NAS. Table 2 shows the percent of GA PIREPs based on the total number of reports in the data set. GA reports make up a slightly higher fraction $(39.6 \%)$ when only considering reports that had an aircraft type identified.

Entry method is dominated by the nominal category, but AWC-WEB entry accounts for a relatively significant number of entries. Overall, AEROVIE reports represent $0.3 \%$ of all reports, and AWC-WEB amounts to $13 \%$ of all reports. PIREPs submitted other than with AEROVIE or AWC-WEB will be referred to as nominal reports. Table 3 breaks down the GA report submission by entry method. Usage of the AEROVIE app is higher in the GA population than the overall population, whereas there is a decreased usage of the AWC-WEB interface by the GA community, as it is targeted to commercial airlines. Annual counts of total and GA reports for the period of record are shown in Fig. 2. Both the total and GA count increased from 2015 to 2017, but the growth rate in both flattened thereafter. The diurnal variation in PIREP report frequency shows an expected overnight minimum in reports and an afternoon peak, yet the total PIREP frequency peaks earlier in the day than the GA PIREPs (Fig. 3).

\section{2) GEOGRAPHIC REPORTING FREQUENCIES}

PIREP-reporting frequencies were geographically categorized by states/territories and FAA ARTCCs for the GA reports. Quantum-GIS (QGIS 2015) was used to import appropriate shapefiles of United States and FAA ARTCC regions and generate counts of the reports within the boundaries of all features for the 5-yr period of record. The counts were normalized into a density by dividing by the feature area (in units of $100 \mathrm{~km}^{2}$ ) and divided by $5 \mathrm{yr}$ to achieve a density of reports per year. Additionally, the state counts were normalized by the average annual reported flight hours for the years 2012-2015 into a report rate. The densities for states/territories and ARTCCs are given in Fig. 4 and Fig. 6, respectively, and the reporting rates for states normalized by annually averaged flight hours are given in Fig. 5. A caveat for the density values is that the calculation is based on the geographic boundaries in the shapefile, not including nearby waterways, and is subject to the accuracy of the reported location. The eastern states of the United States tend to show a higher density in GA reports in both the states/territories and ARTCC regions, whereas the Intermountain West and Alaska have lower densities. Accounting for the GA activity by state (Fig. 5) indicates that Alaska has the highest report rate even though the report density is low. It is worth noting that special efforts to improve PIREP solicitation and dissemination were initiated in 2014 by the Alaska PIREP Improvement Initiative (NTSB 2017).

\section{3) PIREP SECTION REPORTING FREQUENCIES AND PIREP LENGTH}

An evaluation of the frequency of entry of each PIREP section was conducted for the period of record. Frequencies for the non-mandatory sections are included in Fig. 7 and segregated by nominal versus GA reports as well as the reporting method. The most striking aspect of this analysis is the higher overall rates of entry for COTS-based Aerovie reports. The Aerovie app use of icons could help explain this result as Johnson et al. (2018) indicated that pilots looked favorably upon icon usage in a PIREP submittal tool for ease of use as well as to represent varied weather 
Table 2. PIREP classification for 2015-2019 by number and percentage.

\begin{tabular}{|c|c|c|c|c|c|c|}
\hline $\begin{array}{c}\text { Total } \\
\text { PIREPS }\end{array}$ & Nominal & AEROVIE & AWC-WEB & GA & $\begin{array}{c}\text { Aircraft } \\
\text { Unidentified }\end{array}$ & $\begin{array}{c}\text { Aircraft } \\
\text { Identified }\end{array}$ \\
\hline 2803321 & 2436395 & 7474 & 359452 & 1049181 & 162692 & 2640629 \\
& $(86.9 \%)$ & $(0.3 \%)$ & $(12.8 \%)$ & $(37.4 \%)$ & $(5.8 \%)$ & $(94.2 \%)$ \\
\hline
\end{tabular}

Table 3. GA PIREP classification for 2015-2019 by number and percentage.

\begin{tabular}{|c|c|c|c|}
\hline Total GA PIREPS & Nominal & AEROVIE & AWC-WEB \\
\hline 1049181 & 983619 & 7151 & 58411 \\
& $(93.7 \%)$ & $(0.7 \%)$ & $(5.6 \%)$ \\
\hline
\end{tabular}

conditions. AWC-WEB has notably lower rates of entry than other reporting methods in the sky condition (/SK) and the flight visibility and weather (/WX) sections. The highest entry rates noted are for Aerovie reports of turbulence at nearly $90 \%$. The most uniformity in entry rates amongst the entry methods are for the remark (/RM) section. The largest differentials in entry rates occur in the /WX and the wind direction and speed (/WV) sections.

The PIREP / RM section provides pilots a way to provide supplemental information to preceding sections or report information not contained within the preceding sections. We assessed the length of the PIREP and the / RM section in terms of the number of characters. The reports from the Aerovie app, almost exclusively used by GA, contain more characters overall and within the /RM section than observed in nominal or AWC-WEB reports. This result could be simply a tendency for GA pilots to be less concise when reporting information in the application. It is important to note that the information content quality is not evaluated here, and caution is suggested in assuming PIREPs with longer character lengths indicate higher quality content information.

\section{b. PIREP consistency and quality checks}

\section{1) TERRAIN CHECK}

Terrain elevation data were used to provide a basic check that the reported flight level (/FL) was above the local terrain. Common errors in flight level include typographical errors or the use of AGL in the /FL section of the report. As noted earlier, GMTED with 30 arc-sec (approximately 1-km) resolution were used for this basic check. Based on the reported location of the PIREP, the flight level was compared to the minimum elevation provided at the closest GMTED grid point as well as

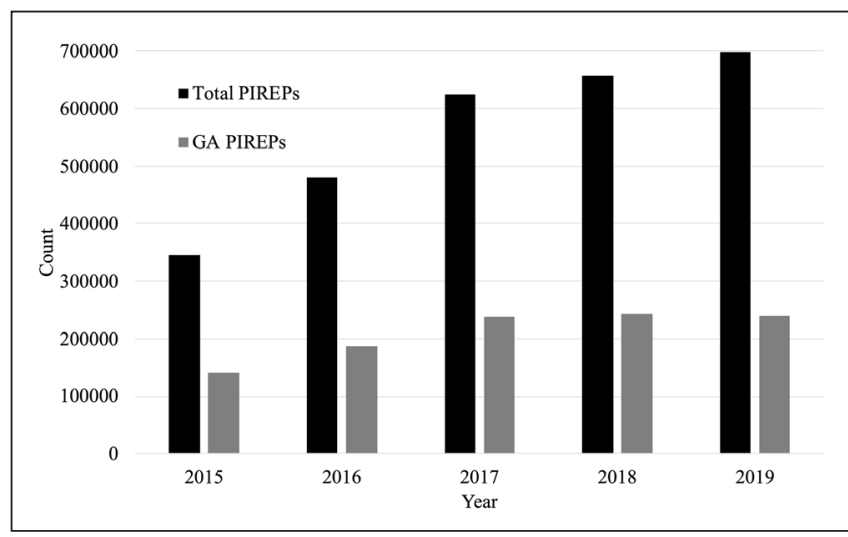

Figure 2. PIREP annual counts for the years 2015-2019 for total (black) and GA (gray).

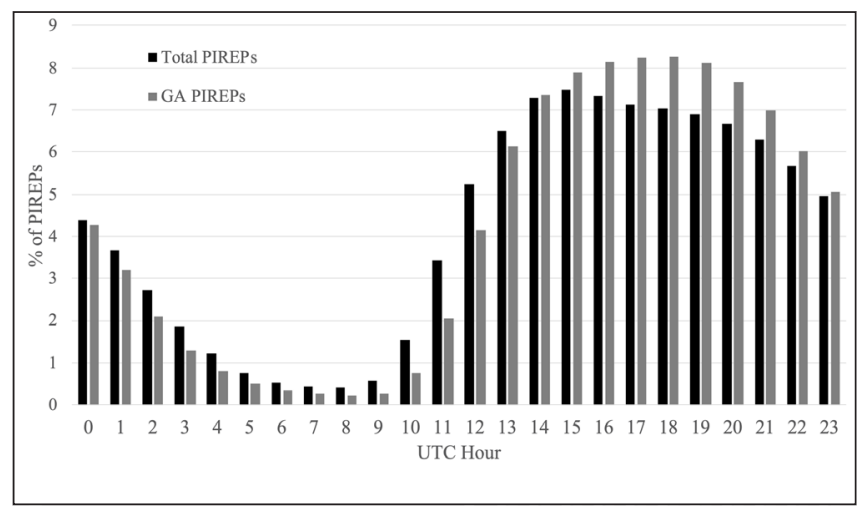

Figure 3. PIREP frequency during 2015-2019 by hour for total (black) and GA (gray).

the minimum reported within a $10-\mathrm{km}$ radius. The later was used to allow for some uncertainty in the reported location. Results of this analysis show that GA reports had a higher failure rate for this check as compared to nominal reports (Fig. 8). AWC-WEB and the Aerovie reports have a notably lower failure rate. The use of the $10-\mathrm{km}$ radius resulted in a significant reduction in the failure rate and indicates that the locational accuracy 


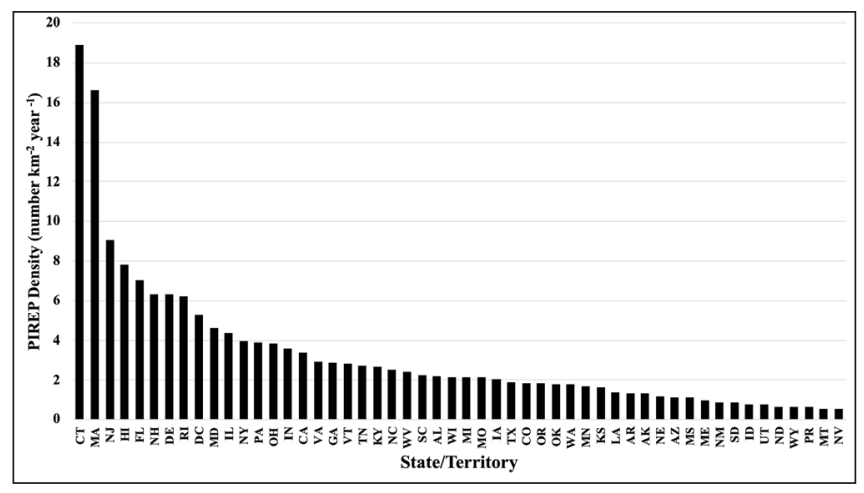

Figure 4. GA PIREP density (number $\mathrm{km}^{-2} \mathrm{yr}^{-1}$ ) by State/Territory (2015-2019).

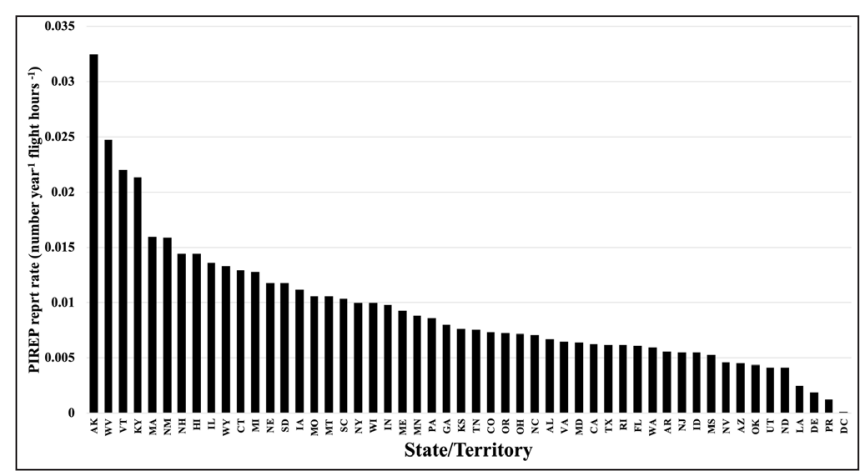

Figure 5. GA PIREP report rate (number $\mathrm{yr}^{-1}$ flight $\mathrm{h}^{-1}$ ) by state/territory (2015-2019). Flight hours based on averages for the years 2012-2015.

is a significant factor. Analysis of the geolocations of the errors (not shown) indicates regions of complex terrain have higher error rates, and the use of a more liberal search radius is warranted. The use of /FL000 is a contributing factor to the error rate when it is being used to indicate "surface" or "ground" at locations above sea level. About 1 in 123 PIREPs make use of the /FL000 to report altitude. Notably, Aerovie reports included only one such usage in all their reports, and AWC-WEB reports also had lower usage with a rate of only 1 in 533 PIREPs.

\section{2) PIREP REPORT TIME FREQUENCY}

Temporal precision of the reported time was evaluated by counting the occurrences of PIREPs by minute of the hour. An expectation would be that reports are submitted randomly within the hour and that the frequency counts for each minute should be relatively constant. Similarly, storm report data from the Storm Prediction Center (SPC, courtesy of Harold Brooks), another type of crowd-sourced weather information,

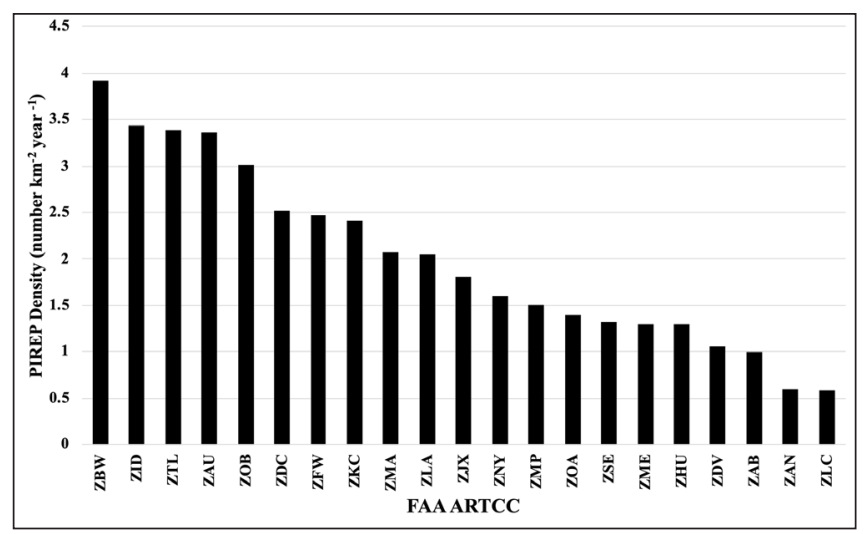

Figure 6. GA PIREP density (number $\mathrm{km}^{-2} \mathrm{yr}^{-1}$ ) by FAA ARTCC (2015-2019).

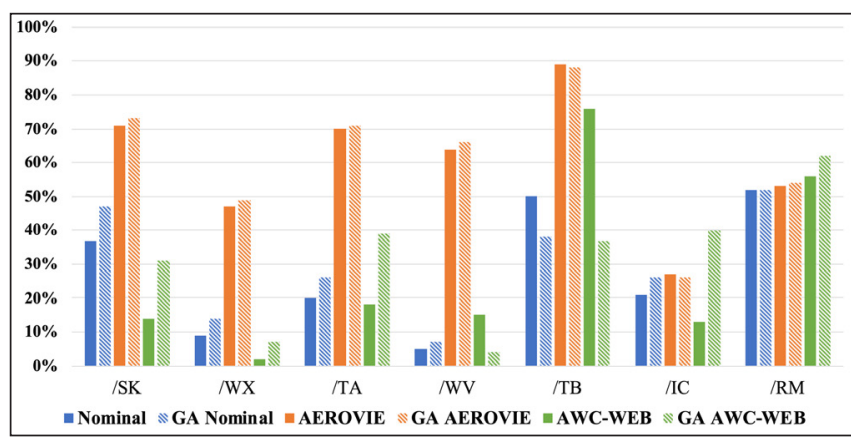

Figure 7. Frequency of entry of PIREP non-mandatory sections for nominal (blue), AEROVIE (orange), AWC-WEB (green) by all reports (solid) and GA only (hatched).

were analyzed for context. Figure 9 compares the frequency count by minute of the PIREPs and storm reports. Minutes of the hour that are multiples of five have higher report frequencies than other minutes, especially for the top of the hour and $30 \mathrm{~min}$ after the hour. Storm reports have a noticeable increase at the 15min and 45-min times as compared to the PIREPs. The differences in frequencies between the min and 5-min PIREPs is smaller than for the storm reports indicating that the PIREPs have better time resolution, but there is still a significant amount of rounding of the report time.

\section{3) PIREP ICING TYPE AND TEMPERATURE CHECK}

A check of the reported air temperature associated with each PIREP that included an icing type was conducted to provide a more global check of the quality of PIREP icing-type reports. Aviation weather training and educational guidance frequently use the expected temperature ranges for the three types of structural 


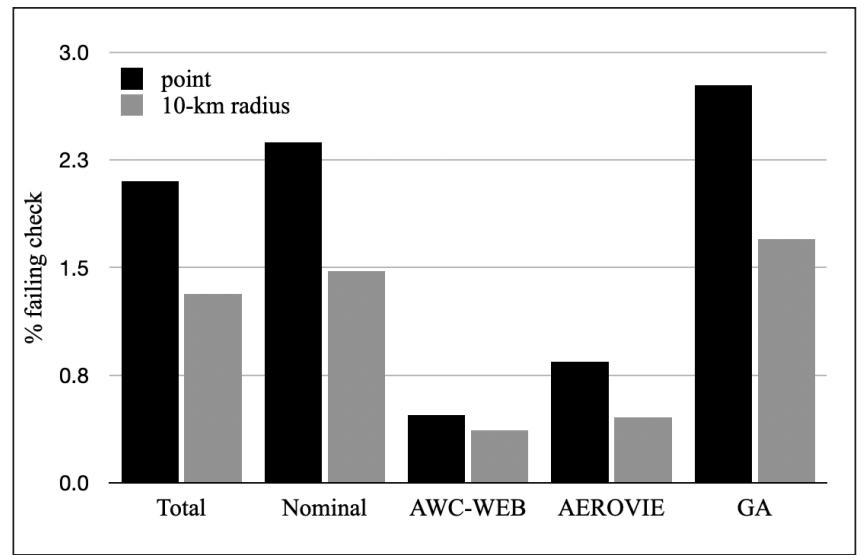

Figure 8. Failure rate for the terrain check using point terrain elevation (black) and minimum terrain within 10 km (gray).

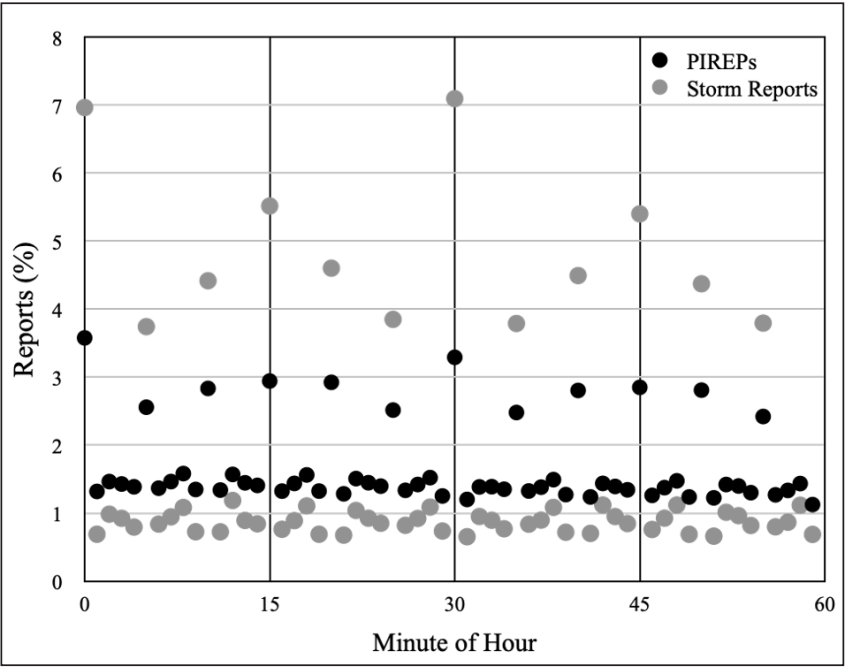

Figure 9. Frequency rate by min of PIREPs (black) and SPC storm reports (gray).

icing. Though slight variation in these expected temperature ranges can be found, the ranges used by the FAA (2021c) and the AWC (AWC 2019) for icing type are used here for illustration. Clear icing, rime icing, and mixed icing are noted to generally occur between $-10^{\circ} \mathrm{C}$ and $2^{\circ} \mathrm{C},-15^{\circ} \mathrm{C}$ and $-10^{\circ} \mathrm{C}$, and $-20^{\circ} \mathrm{C}$ and -15 ${ }^{\circ} \mathrm{C}$, respectively. These ranges do not account for cloud type (e.g., cumulus vs. stratus), but PIREPs infrequently include such specification of cloud type. Clear icing reports (Fig. 10) are largely within the expected temperature ranges. Some of the outliers include cases where temperatures were reported in Fahrenheit instead of Celsius, which is a common transcription error. Rime and mixed icing (Fig. 11 and Fig. 12) show a significant proportion of the reports occur outside of the general temperature ranges anticipated. Mixed icing appears

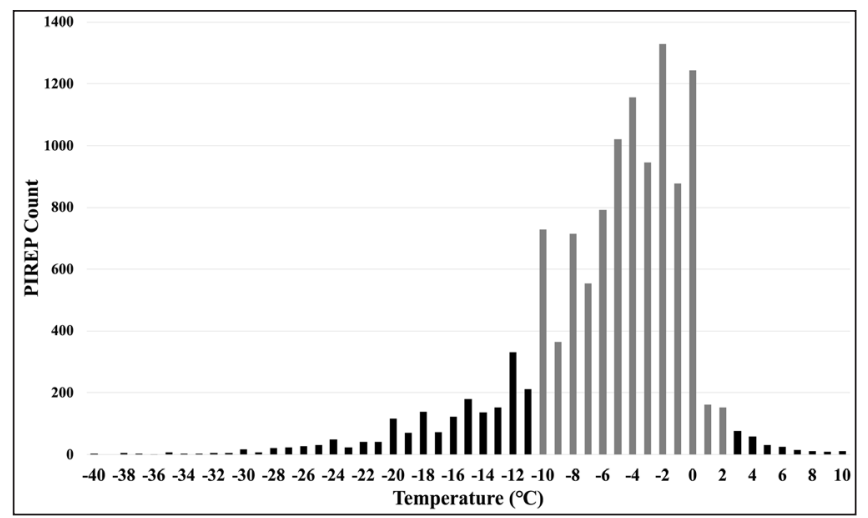

Figure 10. Frequency count of clear icing for GA PIREPs with gray shading for reports within the AWC general temperature guidance.

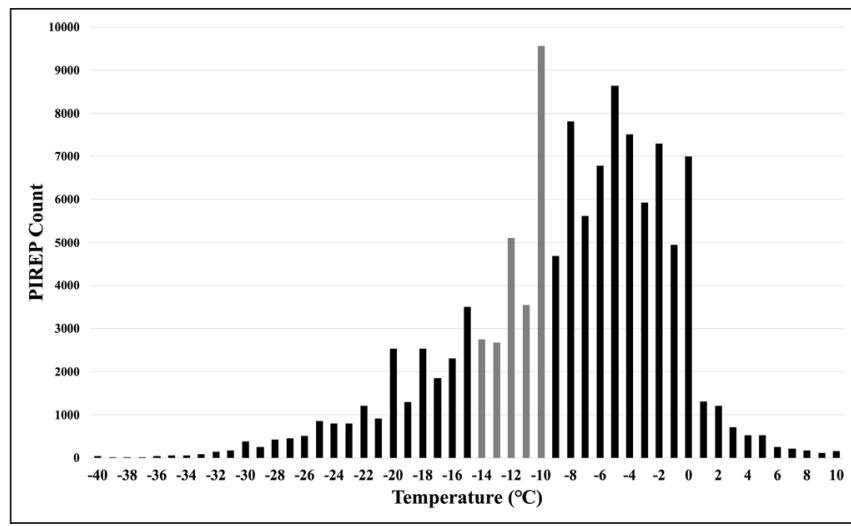

Figure 11. As in Fig. 10 but for mixed icing.

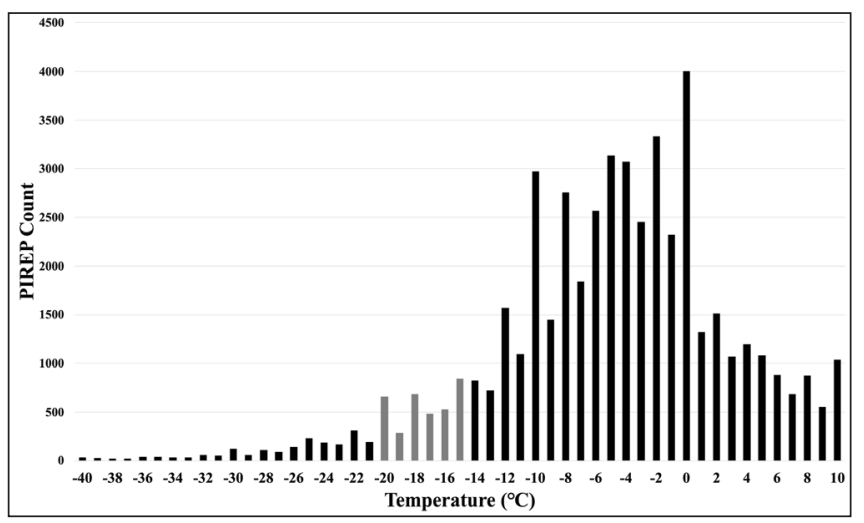

Figure 12. As in Fig. 10 but for rime icing.

to have a more significant number of reports entered for temperatures greater than freezing, perhaps because of a larger number of issues with the reported units of temperature, but why this would be the case for this specific category of icing is unknown. The frequency histograms of the three categories are similar, and the expected temperature ranges may be less relevant in 
evaluating the consistency of the icing type reports. Alternatively, this may indicate a gap in pilots' ability to correctly report icing type.

\section{4) NCEP/NCAR REANALYSIS TEMPERATURE CONSISTENCY CHECK}

Another consistency check is provided by comparing the PIREP temperature reports to those from the NCEP/ NCAR reanalysis. The analysis is only an estimate of the atmospheric state and is not without error. The reanalysis is only available every $6 \mathrm{~h}$, and data from a nearest time (+/-3-h window) were used to compare to each report. Additionally, a subset of PIREPs was used to compare to the reanalysis within a smaller time window (+/- $30 \mathrm{~min})$ of the analysis times. Reanalysis data are available at the following pressure levels (in $\mathrm{hPa}$ ), and temperature data were vertically interpolated from the reported flight level: 1000.0, 925.0, 850.0, $700.0,600.0,500.0,400.0,300.0,250.0,200.0,150.0$, $100.0,70.0,50.0,30.0,20.0$, and 10.0. The temperature difference (PIREP - Reanalysis) is shown in Fig. 13 for the $+/-3$-h window and included 423491 samples. The temperature difference category with the highest frequency is $+1^{\circ} \mathrm{C}$, and the overall temperature bias is $+2.3^{\circ} \mathrm{C}$. Temperature unit report errors (i.e., ${ }^{\circ} \mathrm{F}$ versus ${ }^{\circ} \mathrm{C}$ ) could be responsible for some portion of this bias/ skew towards warmer temperatures, as the temperature ranges typically reported by pilots are in Fahrenheit, which will be larger than for Celsius. The temperature bias when using the more restrictive temporal window is nearly the same $\left(+2 \cdot 4^{\circ} \mathrm{C}\right)$. Biases were calculated for each restricted time window centered on 0000,0600 , 1200, and 1800 UTC (Table 4). The bias for the 1200 UTC window is slightly lower than the other time windows. This is the only time window in which the bias is statistically different from the other time windows using a two sample T-test with a pooled variance and alpha of .05.

Pilots are directed to report the outside air temperature (OAT) for PIREPs (FAA 2021b). The static air temperature measurement, often used interchangeably with OAT, is impacted at higher aircraft speeds by aerodynamic frictional heating of the temperature sensor and adiabatic compression of the air flow (e.g., Petrakou et al. 2006). Ballish and Kumar (2008) reported overall warm biases of up to $1^{\circ} \mathrm{C}$ in aircraft-reported temperatures, noting that biases were a function of phase of flight, aircraft type, and sensor

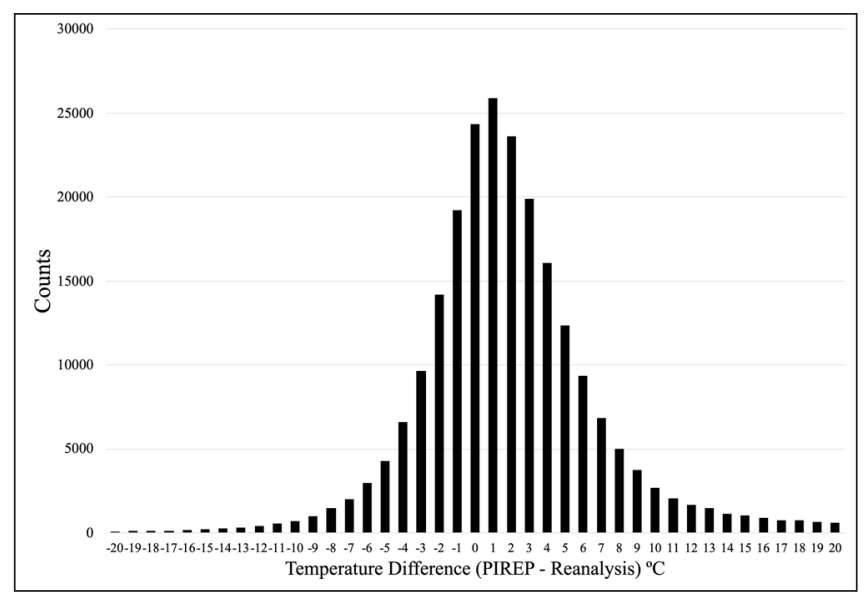

Figure 13. Frequency counts of the temperature difference (PIREP - Reanalysis, ${ }^{\circ} \mathrm{C}$ ) for GA PIREPs from 2015-2019.

type. The warm bias noted in this study could partially be explained by these effects.

\section{5) PIREP TURBULENCE INTENSITY CONSISTENCY CHECK}

The PIREP turbulence intensity consistency with the GTG estimates was evaluated using contingency table analysis (Table 5). The percent correct (where PIREP category agreed with the GTG) was $46.5 \%$, and $83.5 \%$ of data were within one turbulence intensity category. The relation between the PIREP and GTG turbulence intensity was tested with a chi-square test of independence. The relationship was significant: $\chi^{2}$ $($ degrees of freedom $=12, \mathrm{~N}=72801)=11$ 180.63, $\mathrm{p}$ $<0.00001$. Two scores based on the chi-square statistic were used to evaluate the level of agreement between the PIREPs and the GTG. The first is the contingency coefficient (e.g., Janes 2001), and the second is the Cramér's V (Cramér 1946). The Cramér's V statistic generally ranges from 0 to 1 , and this range of values is used as a metric to describe levels of association between variables ranging from no association to very strong (Akoglu 2018). The contingency coefficient was observed to be 0.37 , and the Cramér's V was 0.23 indicating strong levels of association between the observations and the GTG. Considering the offdiagonal frequencies in the contingency table, counts in the lower-left diagonal (24 655) are greater than the upper-right diagonal (13 929) indicating that there is a bias for the PIREP turbulence intensity to be greater than the GTG product. 
Table 4. Temperature bias (PIREPs - NCEP Reanalysis) by analysis hour using a +/- 30-min window.

\begin{tabular}{|c|c|c|c|}
\hline UTC Hour & Bias $\left({ }^{\circ} \mathbf{C}\right)$ & \# Samples & Standard Deviation \\
\hline 0000 & +2.42 & 45174 & 6.71 \\
\hline 0600 & +2.52 & 2249 & 6.89 \\
\hline 1200 & +2.06 & 15582 & 6.63 \\
\hline 1800 & +2.39 & 29579 & 6.51 \\
\hline
\end{tabular}

Table 5. Contingency table for turbulence intensity estimates from PIREPs and the 1-h GTG forecast for 2019.

\begin{tabular}{|l|c|c|c|c|c|c|}
\hline GTG PIREP & None & Light & Moderate & Severe & Extreme & $\begin{array}{c}\text { Marginal } \\
(\%)\end{array}$ \\
\hline None & 12759 & 4239 & 3531 & 13 & 0 & 28.5 \\
\hline Light & 6526 & 4123 & 5790 & 51 & 0 & 22.9 \\
\hline Moderate & 7164 & 7471 & 16511 & 305 & 0 & 43.6 \\
\hline Severe & 458 & 512 & 2330 & 104 & 0 & 4.7 \\
\hline Extreme & 38 & 29 & 125 & 2 & 0 & 0.3 \\
\hline Marginal (\%) & 37.4 & 22.7 & 39.2 & 0.7 & 0.0 & 100.0 \\
\hline
\end{tabular}

\section{6) PIREP ICING CONSISTENCY CHECK}

For the year of 2019, icing intensity reports from PIREPs were compared to nearest estimates from the CIP icing intensities (i.e., icing severity). The data were evaluated using contingency table analysis (Table 6) similar to that conducted for the turbulence intensity analysis. The percent correct (where PIREP category agreed with the CIP) was $38.4 \%$, a worse value than that for the turbulence intensity evaluation. The relation between the PIREP and CIP icing intensity was also tested with a chi-square test of independence. The relationship was significant: $\chi^{2}$ (degrees of freedom $=9$, $\mathrm{N}=37,052)=571.81, \mathrm{p}<0.00001$. The contingency coefficient was observed to be 0.12 , and the Cramér's $\mathrm{V}$ was 0.07 indicating weak levels of association between the observations and CIP. Whereas trace icing intensity reports accounted for $70 \%$ of the PIREPs in this comparison, only $39 \%$ of the CIP were in the trace category. The CIP frequencies were more evenly spread between nil, trace, and light icing relative to the sharp peak in the trace category for PIREPs noted in the marginal probabilities. This may indicate a limit to the precision of pilots' icing intensity estimates and/or the CIP product. It is possible, for example, that trace icing is being over-reported by pilots, and that the CIP may be overanalyzing regions of trace icing. Unlike turbulence intensity, the off-diagonal frequencies do not indicate a significant bias between the PIREP icing intensity in comparison to the CIP, but there is a larger fraction of data $(61.6 \%)$ in the off-diagonal bins as compared to that for turbulence intensity (53.5\%).

\section{Conclusions}

Examination of PIREPs in this study, with a particular emphasis toward general aviation, was conducted for the 2015-2019 period. An array of assessments including report frequency analysis and logical range as well as more quantitative checks provide a view of GA PIREP quality. COTS technology is seen to have beneficial aspects in terms of the quantity of non-mandatory sections reported as well as limiting some types of entry errors. Assessment of meteorological phenomena, focused on icing and turbulence, indicate some potential gaps in information quality. The following are noted results of this analysis.

- GA PIREP-reporting frequency had been increasing, but the trend has recently flattened (prior to the COVID-19 pandemic period). PIREP reporting frequency by state, when accounting for GA activity, was highest in the state of Alaska and may be a testament to efforts there to promote use of PIREPs.

- Potential errors in reported flight altitude have a significant contribution from the use of $/$ FL000 with the apparent intent to indicate a surface observation. 
Table 6. Contingency table for icing intensity estimates from PIREPs and the CIP for 2019.

\begin{tabular}{|l|c|c|c|c|c|c|}
\hline CIP PIREP & None & Trace & Light & Moderate & Severe & $\begin{array}{c}\text { Marginal } \\
(\mathbf{\%})\end{array}$ \\
\hline None & 938 & 1072 & 605 & 67 & 0 & 7.2 \\
\hline Light & 6177 & 10098 & 8656 & 1031 & 0 & 70.1 \\
\hline Moderate & 1493 & 3030 & 3180 & 528 & 0 & 22.2 \\
\hline Severe & 21 & 49 & 89 & 18 & 0 & 0.5 \\
\hline Extreme & 0 & 0 & 0 & 0 & 0 & 0.0 \\
\hline Marginal (\%) & 23.3 & 38.5 & 33.8 & 4.4 & 0.0 & 100.0 \\
\hline
\end{tabular}

- The reporting frequency of individual nonmandatory PIREP sections was significantly higher in the COTS system.

- PIREP report times show significant rounding to the 5-min interval, which maybecharacteristic of crowd-sourced weather reports, particularly at the hour and half-hour mark and limits the temporal precision of the reports. This may reduce the utility of the reports for some downstream applications including use in data assimilation systems.

- GA PIREP-reported air temperatures for icing reports show relatively weak agreement with the expected temperature ranges for given icing types, especially for rime and mixed icing. Though this result may mainly be due to the limitation of trying to infer icing type with only the use of temperature, pilot accuracy in identifying the icing type might be worthy of further investigation.

- Overall, GA PIREP temperature reports agree well with atmospheric reanalysis values, given the temporal and vertical resolution of the reanalysis product but show a warm bias. This bias may be partly explained by instances of incorrect entry of the temperature in ${ }^{\circ} \mathrm{F}$.

- GA PIREP reports of turbulence intensity have a strong association with the AWC GTG product, though there is a bias towards higher turbulence intensity in the PIREPs compared to the GTG product.

- GA PIREP reports of icing intensity have weak association with the AWC CIP product with noted differences in the (marginal) frequencies in the respective categories between the PIREPs and CIP product.
This study did not evaluate the impact of inaccuracies in PIREPs that are potentially introduced along the submission pathways such as communications with ATC or software used for report entry. Though this might be expected to introduce random error into the PIREPs, the possibility that systematic biases could be introduced cannot be ruled out. Additional study attributing specific features of COTS systems that lead to PIREP-reporting improvements would also be relevant in making recommendations for PIREP submission tool software development.

Acknowledgments. This paper was prepared from a study conducted at Florida Institute of Technology under Project No. 33: Weather Technology in the Cockpit: Augmented Weather Information Project (AWIP), the Federal Aviation Administration (FAA) Air Transportation Center of Excellence Cooperative Agreement 12-C-GA-FIT-030 for the Partnership to Enhance General Aviation Safety, Accessibility and Sustainability (PEGASAS). The FAA neither endorses nor rejects the findings of this research. The authors would also like to thank Dr. Deborah Carstens of the Florida Institute of Technology for her support of these research efforts. 


\section{APPENDIX A}

\section{Most Used GA Gets - General Aviation Manufacturers Association 2016}

\begin{tabular}{|c|c|c|}
\hline ICAO Code & Manufacturer & Model \\
\hline CL30 & BOMBARDIER & $\begin{array}{l}\text { BD-100 Challenger } \\
300\end{array}$ \\
\hline CL30 & BOMBARDIER & Challenger 300 \\
\hline CL35 & BOMBARDIER & $\begin{array}{l}\text { BD-100 Challenger } \\
350\end{array}$ \\
\hline CL35 & BOMBARDIER & Challenger 350 \\
\hline CL60 & BOMBARDIER & $\begin{array}{l}\text { CL-600 Challenger } \\
650\end{array}$ \\
\hline CL60 & BOMBARDIER & Challenger 650 \\
\hline GL5T & BOMBARDIER & $\begin{array}{l}\text { BD-700 Global } \\
5000\end{array}$ \\
\hline GL5T & BOMBARDIER & Global 5000 \\
\hline GL7T & BOMBARDIER & $\begin{array}{l}\text { BD-700 Global } \\
7000\end{array}$ \\
\hline GL7T & BOMBARDIER & Global 7000 \\
\hline GLEX & BOMBARDIER & E-11 \\
\hline GLEX & BOMBARDIER & $\begin{array}{l}\text { BD-700 Global } \\
\text { Express }\end{array}$ \\
\hline GLEX & BOMBARDIER & Global Express \\
\hline $\mathrm{C} 25 \mathrm{~A}$ & CESSNA & 525A Citation CJ2 \\
\hline $\mathrm{C} 25 \mathrm{~B}$ & CESSNA & 525B Citation CJ3 \\
\hline $\mathrm{C} 25 \mathrm{C}$ & CESSNA & 525C Citation CJ4 \\
\hline $\mathrm{C} 500$ & CESSNA & 500 Citation \\
\hline $\mathrm{C} 500$ & CESSNA & 500 Citation 1 \\
\hline $\mathrm{C} 501$ & CESSNA & 501 Citation 1SP \\
\hline $\mathrm{C} 510$ & CESSNA & $\begin{array}{l}510 \text { Citation } \\
\text { Mustang }\end{array}$ \\
\hline $\mathrm{C} 525$ & CESSNA & 525 CitationJet \\
\hline $\mathrm{C} 525$ & CESSNA & 525 Citation CJ1 \\
\hline $\mathrm{C} 526$ & CESSNA & 526 CitationJet \\
\hline $\mathrm{C} 550$ & CESSNA & 550 Citation 2 \\
\hline C550 & CESSNA & 550 Citation 2 \\
\hline C551 & CESSNA & 551 Citation 2SP \\
\hline $\mathrm{C} 560$ & CESSNA & 560 Citation 5 \\
\hline $\mathrm{C} 560$ & CESSNA & 560 Citation 5 \\
\hline $\mathrm{C} 560$ & CESSNA & 560 Citation Ultra \\
\hline C56X & CESSNA & $\begin{array}{l}\text { 560XL Citation } \\
\text { Excel }\end{array}$ \\
\hline C56X & CESSNA & $\begin{array}{l}\text { 560XL Citation } \\
\text { Excel }\end{array}$ \\
\hline
\end{tabular}

\begin{tabular}{|c|c|c|}
\hline ICAO Code & Manufacturer & Model \\
\hline C650 & CESSNA & 650 Citation 3 \\
\hline C650 & CESSNA & 650 Citation 6 \\
\hline C680 & CESSNA & $\begin{array}{l}680 \text { Citation } \\
\text { Sovereign }\end{array}$ \\
\hline $\mathrm{C} 750$ & CESSNA & 750 Citation 10 \\
\hline $900 \mathrm{~F}$ & DASSAULT & Falcon 900 \\
\hline F2TH & DASSAULT & Falcon 2000 \\
\hline FA10 & DASSAULT & Falcon 10 \\
\hline FA10 & DASSAULT & Falcon 100 \\
\hline FA20 & DASSAULT & Falcon 20 \\
\hline FA20 & DASSAULT & Falcon 200 \\
\hline FA50 & DASSAULT & Falcon 50 \\
\hline FA7X & DASSAULT & Falcon $7 \mathrm{X}$ \\
\hline E190 & EMBRAER & Lineage 1000 \\
\hline E190 & EMBRAER & $\begin{array}{l}\text { ERJ-190 Lineage } \\
1000\end{array}$ \\
\hline E35L & EMBRAER & $\begin{array}{l}\text { EMB-135BJ } \\
\text { Legacy } 600\end{array}$ \\
\hline E35L & EMBRAER & $\begin{array}{l}\text { EMB-135BJ } \\
\text { Legacy }\end{array}$ \\
\hline E35L & EMBRAER & $\begin{array}{l}\text { EMB-135BJ } \\
\text { Legacy } 650\end{array}$ \\
\hline E35L & EMBRAER & VC-99B Legacy \\
\hline E35L & EMBRAER & $\begin{array}{l}\text { VC-99B Legacy } \\
600\end{array}$ \\
\hline E50P & EMBRAER & Phenom 100 \\
\hline E55P & EMBRAER & $\begin{array}{l}\text { EMB-505 Phenom } \\
300\end{array}$ \\
\hline E55P & EMBRAER & Phenom 300 \\
\hline GLF4 & $\begin{array}{l}\text { GULFSTREAM } \\
\text { AEROSPACE }\end{array}$ & $\begin{array}{l}\text { G-4 Gulfstream } \\
\text { G300 }\end{array}$ \\
\hline GLF4 & $\begin{array}{l}\text { GULFSTREAM } \\
\text { AEROSPACE }\end{array}$ & $\begin{array}{l}\text { G-4 Gulfstream } \\
\text { G350 }\end{array}$ \\
\hline GLF4 & $\begin{array}{l}\text { GULFSTREAM } \\
\text { AEROSPACE }\end{array}$ & $\begin{array}{l}\text { G-4 Gulfstream } \\
\text { G400 }\end{array}$ \\
\hline GLF4 & $\begin{array}{l}\text { GULFSTREAM } \\
\text { AEROSPACE }\end{array}$ & $\begin{array}{l}\text { G-4X Gulfstream } \\
\text { G450 }\end{array}$ \\
\hline GLF5 & $\begin{array}{l}\text { GULFSTREAM } \\
\text { AEROSPACE }\end{array}$ & $\begin{array}{l}\text { G-5SP Gulfstream } \\
\text { G500 }\end{array}$ \\
\hline GLF6 & $\begin{array}{l}\text { GULFSTREAM } \\
\text { AEROSPACE }\end{array}$ & $\begin{array}{l}\text { G-5SP Gulfstream } \\
\text { G500 }\end{array}$ \\
\hline
\end{tabular}




\section{REFERENCES}

Akoglu, H., 2018: User's guide to correlation coefficients. Turkish Journal of Emergency Medicine. 18, 91-93, CrossRef.

AWC, cited 2019: Three Types of Aircraft Icing, on Twitter, 29 Oct. [Available online at twitter.com/NWSAWC/ status/1189157419227713536.]

Ballish, B. A., and V. K. Kumar, 2008: Systematic differences in aircraft and radiosonde temperatures: Implications for NWP and climate studies. Bull. Amer. Meteor. Soc., 89, 1689-1708, CrossRef.

Bernstein, B. C., F. McDonough, M. K. Politovich, B. G. Brown, T. P. Ratvasky, D. R. Miller, C. A. Wolff, and G. Cunning, 2005: Current Icing Potential (CIP): Algorithm description and comparison with aircraft observations. J. Appl. Meteor. Climatol., 44, 969-986, CrossRef.

Blickensderfer, B., J. Lanicci, T. A. Guinn, J. King, Y. Ortiz, and R. Thomas, 2017: Assessing general aviation pilots' understanding of aviation weather products. The International Journal of Aerospace Psychology, 27, 7991, CrossRef.

Casner, S. M., 2010: Why don't pilots submit more pilot weather reports (PIREPs)? The International Journal of Aviation Psychology, 20, 347-374, CrossRef.

Cramér, H., 1946: Mathematical Methods of Statistics. Princeton University Press, 575 pp.

Danielson, J. J., and D. B. Gesch, 2011: Global multiresolution terrain elevation data 2010 (GMTED2010). USGS Open-File Rep. 2011-1073, 26 pp., CrossRef.

FAA, 2019: Order JO 7110.65Y-Air Traffic Control. FAA, Washington, DC. [Available online at www.faa.gov/ regulations_policies/orders_notices/index.cfm/go/ document.information/documentID/1036234.]

FAA, cited 2021a: General Aviation and Part 135 Activity Surveys. [Available online at https://www.faa.gov/data research/aviation data statistics/general aviation/].

FAA, 2021b: Order JO 7110.10BB-Flight Services. FAA, Washington, DC. [Available online at www.faa.gov/ regulations_policies/orders_notices/index.cfm/go/ document.information/documentID/1036234.]

FAA, cited 2021c: Structural Icing Type. ALC-33: Inflight Icing. [Available online at www.faa.gov/regulations policies/orders notices/index.cfm/go/document. information/documentID/1039722.]

GAMA, 2016: 2016 General Aviation Statistical Databook \& 2017 Industry Outlook. General Aviation Manufacturers Association, Washington, DC. [Available online at gama.aero/wp-content/uploads/2016-GAMADatabook forWeb.pdf.]

GDAL/OGR, cited 2018: GDAL/OGR geospatial data abstraction software library. Open Source Geospatial Foundation, CrossRef.
Gultepe, I., and Coauthors, 2019: A review of high impact weather for aviation meteorology. Pure Appl. Geophys., 176, 1869-1921, CrossRef.

James, E. P., S. G. Benjamin, and B. D. Jamison, 2020: Commercial aircraft-based observations for NWP: Global coverage, data impacts, and COVID-19. J. Appl. Meteor. Climatol., 59, 1809-1825, CrossRef.

Janes, J., 2001: Categorical relationships: Chi-square. Library Hi Tech, 19, 296-298, CrossRef.

Johnson, I., and Coauthors, 2017: PEGASAS: Weather technology in the cockpit. 19th International Symposium on Aviation Psychology, Dayton, OH, aviationpsychology.org, 323-328. [Available online at corescholar.libraries.wright.edu/isap 2017/71.]

, B. Blickensderfer, G. Whitehurst, L. J. Brown, U. Ahlstrom, and M. E. Johnson, 2019: Weather hazards in general aviation: Human factors research to understand and mitigate the problem. 20th International Symposium on Aviation Psychology, Dayton, $\mathrm{OH}$, aviationpsychology.org, 421-425. [Available online at https:// corescholar.libraries.wright.edu/isap_2019/71.]

Johnson, M. E., Y. Gu, and Y. Feng, 2018: Exploratory study on features for a PIREP submittal tool: Preliminary results. Presentation, Friends \& Partners in Aviation Weather 2018 Fall Meeting, Orlando, FL, National Business Aviation Association. [Available online at ral. ucar.edu/sites/default/files/public/events/2018/friendsand-partners-in-aviation-weather/docs/m-pitts-final-r1. pdf.]

Kalnay, E., and Coauthors, 1996: The NCEP/NCAR 40-year reanalysis project. Bull. Amer. Meteor. Soc., 77, 437471, CrossRef.

NTSB, 2017: Improving pilot weather report submission and dissemination to benefit safety in the national airspace system. NTSB/SIR-17/02 PB2017-101424, National Transportation Safety Board, Washington DC. 68 pp. [Available online at ntsb.gov/safety/safetystudies/Documents/SIR1702.pdf.]

Office of the Federal Coordinator for Meteorological Services and Supporting Research (OFCM), 1998: Federal meteorological handbook no. 12: United States meteorological codes and coding practices. FCM H12-I998, updated 2019, U.S. Dept. of Commerce/ National Oceanic and Atmospheric Administration, Washington, DC. [Available online at www.icamsportal.gov/publications/fmh/FMH12/fmh12.pdf.]

Petrakou, K., E. Narlis, and S. Voliotis, 2006: Algorithmic air data computer model for general aviation light aircraft. Proceedings, International Symposium ELMAR, Zadar, Croatia, IEEE, 219-222. CrossRef.

QGIS, 2015: QGIS geographic information system. Open Source Geospatial Foundation Project. [Available online at qgis.org/en/site/.] 
Schwartz, B., 1996: The quantitative use of PIREPs in developing aviation weather guidance products. Wea. Forecasting, 11, 372-384. CrossRef.

Sharman, R., C. Tebaldi, G. Wiener, and J. Wolff, 2006: An integrated approach to mid- and upper-level turbulence forecasting. Wea. Forecasting, 21, 268-287. CrossRef.

, L. B. Cornman, G. Meymaris, J. Pearson, and T. Farrar, 2014: Description and derived climatologies of automated in situ eddy-dissipation-rate reports of atmospheric turbulence. J. Appl. Meteor. Climatol., 53, 1416-1432. CrossRef.

Vietor, D., 2018: NWS Aviation Weather Center PIREP Initiative Update. Presentation, Alaska Weather and Aviation Connection Workshop, Anchorage, AK, Anchorage Center Weather Service Unit. [Available online at www.weather.gov/media/zan/Vietor $\% 20-\% 20$ Day\%201\%20-\%20AWC\%20PIREP\%20Tool.pdf.]

Wickham, J., C. Homer, J. Vogelmann, A. McKerrow, R. Mueller, N. Herold, and J. Coulston, 2014: The multiresolution land characteristics (MRLC) Consortium 20 years of development and integration of USA national land cover data. Remote Sens., 6, 7424-7441. CrossRef. 